\title{
The role of optimization models for rescue vehicles routes in evacuation
}

\author{
A. Polimeni \\ DIMET, Dipartimento di Informatica, Matematica, Elettronica e \\ Trasporti, Università degli Studi Mediterranea di Reggio Calabria, Italy
}

\begin{abstract}
In this paper a review on path and route optimization for rescue vehicles is reported. Starting from general considerations on risk in transport networks, the models and the procedure applied to simulate or optimize an evacuation are analysed. The path and the route optimization were examined, considering the one-to-one approach and the vehicle routing.

Keywords: rescue vehicles, vehicle routing, optimization models.
\end{abstract}

\section{Introduction}

In road evacuation, various fields can be considered: demand analysis [1, 2], demand-supply interaction [3], planning [4-8] and path/route optimization [9].

The path/route optimization (considering as path the trip between two points, as route a trip chain with some intermediate points) is a problem much discussed in literature. This problem can be formalized for specific vehicle classes, such as rescue vehicles (ambulances, fire engine and so on). There are many approaches used to define and tackle the problem, depending on the type of results sought. So, considering for example the objective function, the path travel cost or the path travel time or their combination can be optimized. For these reasons, the aim of this paper is to furnish a review on path/route optimization for rescue vehicles in an evacuation. The path (and/or the route) of a rescue vehicle that moves on a network can be chosen by two decision-makers: the driver or an external decision-maker. In the first case the decision derives from the driver's experience and/or from the use of an instrument able to capture the network characteristics (i.e. a GPS navigator). In the second case the decision-maker informs the driver of the path to follow. In order to follow the best decision, the 
decision-maker has to be supported by a system that receives real time information, optimize the paths in real time, and communicates it to the driver. The real-time information allows knowing the instantaneous state of network and re-optimizing the paths both for private vehicles and rescue vehicles.

In section 2 the literature review on path/route optimization is considered, analysing the risk in a transport system. Two approaches are considered: the first is the one-to-one approach for the path optimization; the second is the vehicle routing approach (or one-to-many) for the route optimization. In section 3, some conclusions are reported.

\section{Routing methodologies}

Risk analysis in transport systems allows planning the activities to perform in emergency situations (rescue people, resource allocation and distribution and so on). To perform this activities, demand analysis [10-12], supply [13], demandsupply interaction [3, 14-16], route optimization [9, 17, 18], land use studies [19] are necessary. A systematic analysis of the risk theory applied to transport systems is reported in [20]. In other studies are treated just specific aspects referring to the case of an emergency at wide scale as an example due to the threat of a nuclear disaster [21], or to the generic risk in an urban transport system [22]. Some works investigate the effectiveness of using traffic simulators for optimal scheduling of evacuation operations [23, 24]. Moreover, some tools have been developed to simulate the evacuation scenarios [25].

In emergency conditions, the network optimization can be also performed; the aim is reserving one or more lanes along paths optimized for rescue vehicles [26]. Other topics refer to the network evaluation (reliability, vulnerability, accessibility) to optimize the medical supplies location [27]. In general, the models and the algorithms used in ordinary conditions [28, 29] cannot be applied to the case of emergency conditions [20]. Similarly for the path search: a large literature in the case of ordinary conditions is present [30-32] but only few works [33-35] are present in the particular case in which the conditions of a transport system are modified due the happening of an emergency.

In transport models, several classes of users can be considered, for example in [36] four classes are defined to establish assignment rules. Referring to the specific case of path optimization in evacuation conditions, two classes of users could be considered: users who in an evacuation go out alone from the area, users who need help to go out alone from the area. In the first case, the evacuees use private vehicles; in the second case the evacuees are rescued using rescue vehicles (ambulances, buses as so on). Moreover, the path optimization can be tackled considering the current network state or modifying the network (network optimization) to optimize the path of a vehicle class.

In the specific field of rescue vehicles [9], the path search problem can be treated with two main approaches:

1. one-to-one, to optimize paths that connect one origin to one destination (i.e. an ambulance which transport one person once); 
2. vehicle routing, for the connection of one origin to many destinations (i.e. a bus which transport more than one person).

The vehicle routing problem is an extension of the one to one problem because in each pair of nodes to visit a one to one problem has to be solved.

In the next subsections, a literature review on path search and routing problem is reported.

\subsection{One-to-One}

The One-to-One Problem (OOP) [9, 17, 18] consists on find the best path between an origin and a destination. In the field of the path search two topics can be considered: 1) the search of the non-congested shortest path between an origin and a destination; 2) the search of the shortest path perceived by the road user. In the first case, the analyst, starting from the road network, looks the shortest path between each origin/destination pair considering the cost functions associated at the network links. In the second case, the analyst tries to simulate the path followed by the user searching in some choice sets of possible paths; the choice sets can be defined using several methods to define the costs. This case, considering that a subset of paths in the choice sets is perceived by users, has been treated in literature. Two different phases can be distinguished $[32,38]$ : 1) generation of a choice set and 2) path choice among the alternatives belonging to the choice set.

In the literature several algorithms may be found to solve the path search problem [9]. These procedures allow the generation of feasible paths (differing from each other) on a transport network and the definition of the only choice set (mono-set) or all the possible attractive sets (multi-sets). In considering the mono-criterion approach for path generation, exact (shortest paths, k-paths, $\alpha$ paths) or heuristic algorithms could be used [9]. Under the multi-criteria approach, the above exact algorithms (which generate not outstanding paths) or heuristic algorithms could be applied [9].

Referring to ordinary conditions of the network, in the literature there are several applications of these procedures [39, 40] also for time-varying network $[41,42]$ and for rescue vehicles signal pre-emption [43], dispatching [44] and interaction with regular vehicles in an urban context [45].

Therefore few works treat the one-to-one path search problem in emergency conditions [46]. As in ordinary conditions, even in emergency conditions, the user behaviour can be influenced by real time messages. In [47] users' choices are analysed according to how information is disclosed.

In [48] an attempt to define an architecture that allows a control centre to provide real-time information to users and to rescuers involved in the evacuation is reported.

Under emergency conditions, Takahashi et al. [34] propose a model that simulates the variations in user path choice behaviour when, due to a calamitous event, the road network has limited accessibility. The model entails estimating the variation in costs incurred by users who are forced to modify their path choice. Shen et al. [49] propose a user equilibrium approach to analyse the paths toward the safety shelters when some damage has affected the transport network. 
In emergency conditions, the network characteristics can change (i.e. some links are not practicable) and also the link cost can be change in the time [50]. To capture this variability, cost function in time dependent network [51] and algorithms to find the shortest paths $[52,53]$ are developed. In table 1 some papers present in literature are reported and classified.

Table 1: $\quad$ Path search problems classification.

\begin{tabular}{|c|c|c|c|c|c|c|c|c|}
\hline \multirow[t]{2}{*}{ Reference } & \multicolumn{2}{|c|}{ Solution approach } & \multicolumn{2}{|c|}{ Cost functions } & \multicolumn{2}{|c|}{ Path } & \multicolumn{2}{|c|}{ Conditions } \\
\hline & $\mathrm{E}$ & $\mathrm{H}$ & $\mathrm{S}$ & $\mathrm{TD}$ & SP & MP & Ord & Eva \\
\hline [9] & $\mathrm{X}$ & & $\mathrm{x}$ & & $\mathrm{x}$ & & & $\mathrm{x}$ \\
\hline [41] & $\mathrm{X}$ & & & $\mathrm{x}$ & $\mathrm{x}$ & $\mathrm{x}$ & $\mathrm{X}$ & \\
\hline [42] & $\mathrm{x}$ & & & $\mathrm{X}$ & $\mathrm{x}$ & $\mathrm{x}$ & $\mathrm{X}$ & \\
\hline [46] & $\mathrm{X}$ & & $\mathrm{X}$ & & $\mathrm{X}$ & & & $\mathrm{x}$ \\
\hline [49] & $\mathrm{x}$ & & $\mathrm{x}$ & & $\mathrm{x}$ & & & $\mathrm{x}$ \\
\hline$[50]$ & & & & $\mathrm{X}$ & $\mathrm{X}$ & & & $\mathrm{x}$ \\
\hline$[52]$ & $\mathrm{x}$ & & & $\mathrm{x}$ & $\mathrm{x}$ & & & $\mathrm{x}$ \\
\hline [53] & $\mathrm{x}$ & & & $\mathrm{x}$ & $\mathrm{x}$ & & & $\mathrm{x}$ \\
\hline
\end{tabular}

E: exact, H: heuristic; S: static; TD: time-dependent; SP: single path; MP: multiple path; Ord: ordinary; Eva: evacuation

\subsection{Many-to-One}

The many to one approach, schematized in a Vehicle Routing Problem (VRP), regards the necessity to visit a certain number of nodes in a given sequence, leaving from an origin and returning to it, visiting a node exactly once, with the respect of some constraints (i.e. number of users to visit, number of vehicles and their capacity and so on).

Many methods are possible to classify the routing problem, in the next are highlighted the solution approach (exact or heuristic) the cost (static or timedependent), the demand (fixed or dynamic) and the conditions in which the problem is formulated (ordinary or evacuation). In Table 2 some papers present in literature are reported following the specified classification. Others elements of classification in an emergency can be: the dangerous event is happen or not, the rescue vehicles service is delivery (i.e. to deliver medical supply) or pick-up (i.e. to carry out some users). In Figure 1 a schematic representation of these elements is reported.

The literature that concerns the routing problems is very large [54], the problem generally comes place in the terms of a vehicle that it has to distribute some goods to of the retailers $[55,56]$. Several modified VRP, which take into account the possible variables varying, are present in literature. As an example the Dynamic Vehicle Routing Problem (DVRP) considers the travel time variability on the network [57]; the Multi-Depot Vehicle Routing Problem with Time Windows (MDVRPTW) assumes different depots and allows the loading/unloading operations just in the within of a specific time window [58]. Other VRP extension could be considered the Inventory Routing Problem (IRP) that allows the iterative goods delivery to the retailers [59]. Moreover, the problem of capture travellers' route choice adjustments according to information 
Table 2: Routing problems classification.

\begin{tabular}{|c|c|c|c|c|c|c|c|c|}
\hline \multirow[t]{2}{*}{ Reference } & \multicolumn{2}{|c|}{ Solution approach } & \multicolumn{2}{|c|}{ Cost functions } & \multicolumn{2}{|c|}{ Demand } & \multicolumn{2}{|c|}{ Conditions } \\
\hline & $E$ & $\mathrm{H}$ & $\mathrm{S}$ & TD & $F$ & $\mathrm{D}$ & Ord & Eva \\
\hline [57] & & $\mathrm{x}$ & & $\mathrm{x}$ & & & $\mathrm{x}$ & \\
\hline [58] & & $\mathrm{x}$ & $\mathrm{x}$ & & $\mathrm{x}$ & & $\mathrm{x}$ & \\
\hline [60] & & & & $\mathrm{x}$ & $\mathrm{x}$ & & $\mathrm{x}$ & \\
\hline [61] & & $\mathrm{x}$ & $\mathrm{x}$ & & $\mathrm{x}$ & & & $\mathrm{x}$ \\
\hline [62] & & $\mathrm{x}$ & $\mathrm{x}$ & & $\mathrm{x}$ & & $\mathrm{x}$ & \\
\hline [63] & & $\mathrm{x}$ & $\mathrm{x}$ & & $\mathrm{x}$ & & $\mathrm{x}$ & \\
\hline [64] & & $\mathrm{x}$ & $\mathrm{x}$ & & & $\mathrm{x}$ & $\mathrm{x}$ & \\
\hline [66] & & $\mathrm{x}$ & & $\mathrm{x}$ & & $\mathrm{x}$ & $\mathrm{x}$ & \\
\hline [67] & & $\mathrm{x}$ & $\mathrm{x}$ & & $\mathrm{x}$ & $\mathrm{x}$ & $\mathrm{x}$ & \\
\hline [68] & & & $\mathrm{x}$ & & $\mathrm{x}$ & & & $\mathrm{x}$ \\
\hline [69] & $\mathrm{x}$ & & $\mathrm{x}$ & & $\mathrm{x}$ & & $\mathrm{x}$ & \\
\hline [70] & & $\mathrm{x}$ & $\mathrm{x}$ & & & $\mathrm{x}$ & & $\mathrm{x}$ \\
\hline [71] & & $\mathrm{x}$ & $\mathrm{x}$ & & $\mathrm{x}$ & & & $\mathrm{x}$ \\
\hline [72] & $\mathrm{x}$ & & $\mathrm{x}$ & & & $\mathrm{x}$ & & $\mathrm{x}$ \\
\hline [73] & $\mathrm{x}$ & & $\mathrm{x}$ & & & $\mathrm{x}$ & & $\mathrm{x}$ \\
\hline
\end{tabular}

E: exact, H: heuristic; S: static; TD: time-dependent; F: fixed; D: dynamic; Ord: ordinary; Eva: evacuation

is treated in several studies. As an example, in Gao et al. [60] in order to capture the option value of diversion, a routing policy choice model where alternatives correspond to routing policies is proposed. A routing policy is a decision rule that maps from all possible (node, time) pairs to next links out of the node.

In the case of rescue vehicles, under ordinary conditions, in Yang et al. [44] is considered a fleet that intervenes in function of their current position on the network, in order to maximize the covered area and, in the hypothesis that a vehicle covers a date zone, assigning a sequence of nodes to visit in function of the users characteristics. Gendreau et al. [62,63] propose a method for the relocation of rescue vehicles in order to maximize demand served and covered area. Rajagopalan et al. [64] propose a model to determinate the minimum ambulance number and their location to meet the demand for each interval time. For a review on models of location and relocation for ambulances, refer to [65].

Nair and Miller-Hooks [66], propose a multi-objective approach to relocate the emergency medical service in area, considering system uncertainty.

The optimization of human and medical resource can be tackled, in real world, using a dynamic vehicle routing [67] to take into account the possible immediate helping requests. In this approach, also using information technologies, the ambulance routes and the patient assignment at the doctor can be optimized.

In emergency condition, the vehicles can be used to rescue people or for logistic aims (i.e. deliver supplies). Liu et al. [61] to distribute medical supplies and to respond at a large-scale emergency propose a VRP to minimize unmet demand and time delays. In Zhu et al. [68] a vehicle routing problem to optimize the use of a fleet for medical supplies delivery in an emergency is proposed. The problem is formulated to minimize two objectives: the unmet demand and the 


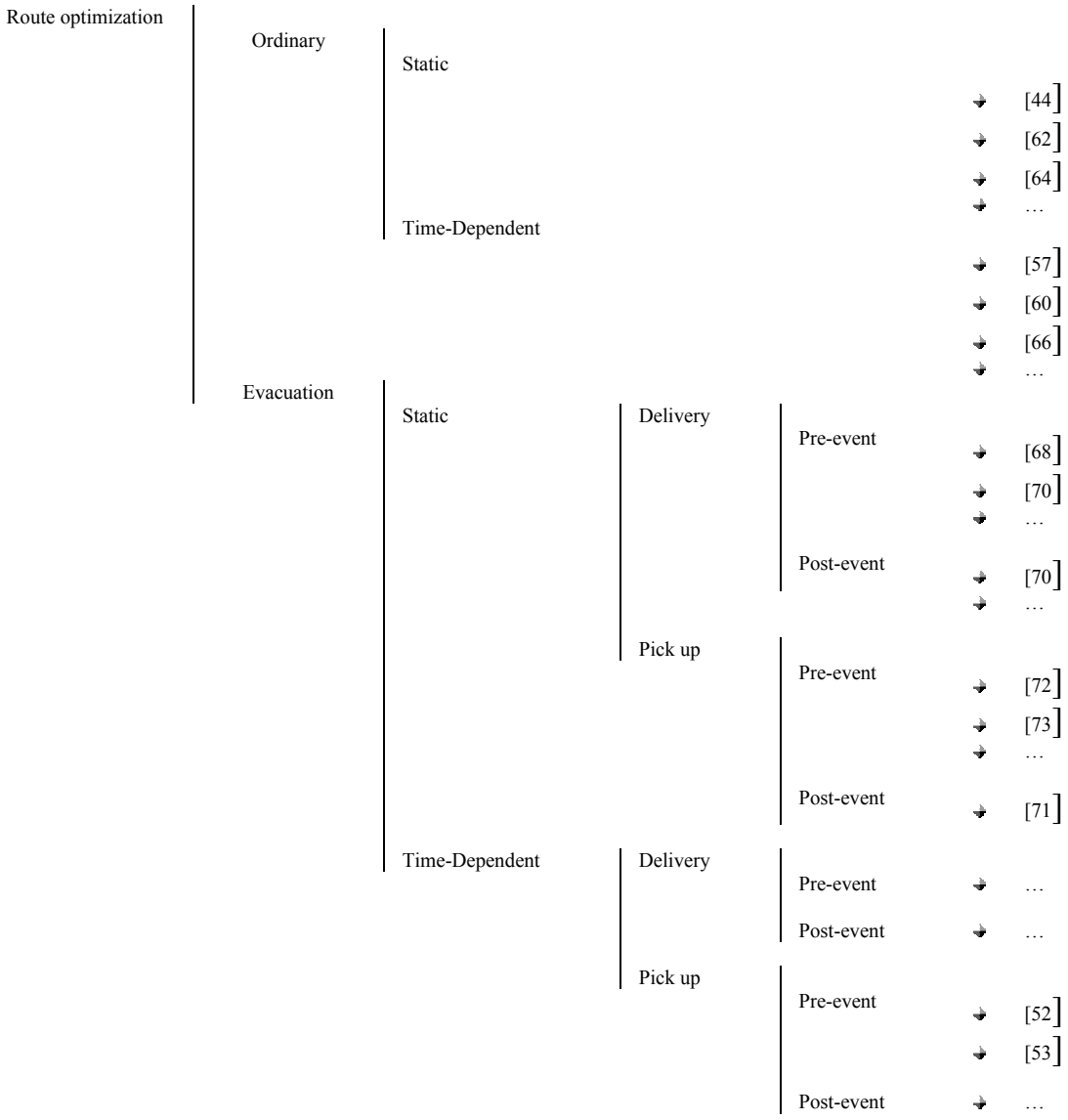

Figure 1: Routing problems and cost functions.

total time. Araz et al. [69] study an emergency system (ambulances and anti-fire vehicles) so as to diminish travel time and maximize the area covered and the number of users saved. Shen et al. [70] propose a VRP to intervene in the case of large scale bioterrorism emergency. The proposed model consists of two stages: planning (the routes are generated in advance for any emergency) and operation (taking into account the information gathered in emergency conditions will make the appropriate changes to the routes determined in the planning stage). Jotshi et al. [71] propose a methodology for the routing and dispatching of rescue vehicles in a disaster scenario, the problem is solved according to the distance between a rescue vehicle and the user in difficulty and as a function of its health conditions.

In Shiwei et al. [72] and Song et al. [73] the buses use to people evacuation in order to minimize the evacuation time, optimizing the buses routes is analyzed. The problem faced also allows the optimization of the number of vehicles, their capacity and their positioning pre-evacuation. To deepening refers to [9]. In some other works, approaches to design a lifeline for rescue vehicles reserving 
them some lanes or giving them priority to intersections [74] are proposed. The contraflow policies allow reconfiguring the network with the objective of minimizing evacuation time [75].

\section{Conclusions}

In this paper, a literature review on route optimization for rescue vehicles in road evacuation is reported. The study start considering the route optimization at two level: at the first the path optimization (one-to-one), at the second the route optimization (many-to-one) are considered. Then, the state of the art analyse the path optimization problem, considering some aspects (as cost functions, solution approach) and the route optimization, considering objectives and solution approaches.

The path optimization is approached as an OOP, the aim to find the best path between an origin and a destination. Some paper related to ordinary conditions (with static and time-dependent cost) are reported; moreover some papers that analyse the path search in emergency conditions when some modification are present in road network and considering the variations in the costs are reported.

The route optimization is approached as a VRP, the aim is to optimize the route which links some intermediate nodes. Some approaches for ordinary conditions are reported, then the emergency conditions are analysed. In emergency conditions the VRP tackle both the medical sources distribution and the people rescue.

\section{References}

[1] Russo F. and Chilà G., Demand models in road evacuation: a synopsis of recent contributions. WIT Transactions on the Built Environment, Volume 116, Urban Transport XVII, Urban Transport and the Environment in $21^{\text {st }}$ Century, Pratelli \& Brebbia C. A. (ed.), WIT Press, Southampton, pp. 601614, 2011.

[2] Russo F. and Chilà G., A statistical approach to analyse user behaviour in road evacuation. WIT Transactions on the Built Environment, Volume 117, Safety and Security engineering IV, Guarascio M., Reiners G. Brebbia C. A. \& Garzia F. (ed.), WIT Press, Southampton, pp. 377-390, 2011.

[3] Vitetta A., Musolino G. and Marcianò F.A., Safety of users in road evacuation: Supply and demand-supply interaction models for users. WIT Transactions on the Built Environment, Volume 96, Urban Transport XIII, Urban Transport and the Environment in the 21st century, Brebbia C. A. (ed.), WIT Press, Southampton, pp. 783-792, 2007.

[4] Russo F. and Rindone C., Safety of users in road evacuation: planning internal processes and guidelines. WIT Transactions on the Built Environment, Volume 96, Urban Transport XIII, Urban Transport and the Environment in the 21st century, Brebbia C. A. (ed.), WIT Press, Southampton, pp. 825-834, 2007. 
[5] Russo F. and Rindone C., Safety of users in road evacuation: the logical framework approach in evacuation planning. WIT Transactions on the Built Environment, Volume 101, Urban Transport XIV, Urban Transport and the Environment in the 21st century, Brebbia C. A. (ed.), WIT Press, Southampton, pp. 751-760, 2008.

[6] Russo F. and Rindone C., Safety of users in road evacuation: Modelling and DSS for LFA in the planning process. WIT Transactions on Ecology and the Environment, Volume 120, Sustainable Development and Planning IV, vol.1, Brebbia C. A. (ed.), WIT Press, Southampton, pp. 453-464, 2009.

[7] Russo, F. and Rindone C., The planning process and logical framework approach in road evacuation: a coherent vision. WIT Transactions on the Built Environment, Volume 117, Safety and Security engineering $I V$, Guarascio M., Reiners G. Brebbia C. A. \& Garzia F. (ed.), WIT Press, Southampton, pp. 415-425, 2011.

[8] Russo, F. and Rindone C , Planning in road evacuation: classification of exogenous activities. WIT Transactions on the Built Environment, Volume 116, Urban Transport XVII, Urban Transport and the Environment in $21^{\text {st }}$ Century, Pratelli \& Brebbia C. A. (ed.), WIT Press, Southampton, pp. 639$651,2011$.

[9] Vitetta A., Quattrone A. and Polimeni A., Safety of users in road evacuation: design of path choice models for emergency vehicles. WIT Transactions on the Built Environment, Volume 96, Urban Transport XIII, Urban Transport and the Environment in the 21st century, Brebbia C. A. (ed.), WIT Press, Southampton, pp. 803-812, 2007.

[10] Russo F. and Chilà G., Safety of users in road evacuation: demand models. WIT Transactions on the Built Environment, Volume 96, Urban Transport XIII, Urban Transport and the Environment in the 21st century, Brebbia C. A. (ed.), WIT Press, Southampton, pp. 773-782, 2007.

[11] Russo F. and Chilà G., Safety of users in road evacuation: RP vs. SP surveys in demand analysis. WIT Transactions on the Built Environment, Volume 101, Urban Transport XIV, Urban Transport and the Environment in the 21st century, Brebbia C. A. (ed.), WIT Press, Southampton, pp. 703$713,2008$.

[12] Russo F. and Chilà G., Safety of users in road evacuation: Modelling and DSS for demand. WIT Transactions on Ecology and the Environment, Volume 120, Sustainable Development and Planning IV, vol.1, Brebbia C. A. (ed.), WIT Press, Southampton, pp. 465-474, 2009.

[13] Praticò F.G., Moro A. and Ammendola R., Potential of fire extinguisher powders as filler in bituminous mixes. Journal of hazardous materials, 173, pp. 605-613, 2010.

[14] Vitetta A., Musolino G. and Marcianò F. A., Safety of users in road evacuation: calibration of cost functions and simulation. WIT Transactions on the Built Environment, Volume 101, Urban Transport XIV, Urban Transport and the Environment in the 21st century, Brebbia C. A. (ed.), WIT Press, Southampton, pp. 715-725, 2008. 
[15] Vitetta A., Musolino G. and Marcianò F.A., Safety of users in road evacuation: Modelling and DSS for transport supply and supply-demand interaction. WIT Transactions on Ecology and the Environment, Volume 120, Sustainable Development and Planning IV, vol.1, Brebbia C. A. (ed.), WIT Press, Southampton, pp. 475-484, 2009.

[16] Marcianò F.A., Musolino G. and Vitetta A., Within day traffic assignment and signal setting in road evacuation: a procedure with explicit path enumeration. WIT Transactions on the Built Environment, Volume 117, Safety and Security engineering IV, Guarascio M., Reiners G. Brebbia C. A. \& Garzia F. (ed.), WIT Press, Southampton, pp. 403-414, 2011.

[17] Vitetta A., Quattrone A. and Polimeni A., Safety of users in road evacuation: algorithms for path design of emergency vehicles. WIT Transactions on the Built Environment, Volume 101, Urban Transport XIV, Urban Transport and the Environment in the 21st century, Brebbia C. A. (ed.), WIT Press, Southampton, pp. 727-737, 2008.

[18] Vitetta A., Quattrone A. and Polimeni A., Safety of users in road evacuation: Modelling and DSS for paths design of emergency vehicles. WIT Transactions on Ecology and the Environment, Volume 120, Sustainable Development and Planning IV, vol.1, Brebbia C. A. (ed.), WIT Press, Southampton, pp. 485-495, 2009.

[19] Russo F. and Musolino G., Urban land-use transport interaction modelling: State of the art and applications. Proc. of WIT Transactions on the Built Environment 96, pp. 525-534, 2007.

[20] Russo F. and Vitetta A., Risk evaluation in a transportation system. International Journal of Sustainable Development and Planning, 1 (2), pp. 170-191, 2006.

[21] Goldblatt R. Development of Evacuation Time Estimates for the Davis Nuclear Power Station. Technical Report 329 KLD, 1993.

[22] Goldblatt R. Evacuation planning. Human factor and traffic engineering perspectives. In Proceedings of the European Transport Conference. Strasbourg, FR, 2004.

[23] Sbayti H. and Mahmassani H.S., Optimal scheduling of evacuation operation. Transportation Research Record: Journal of the Transportation Research Board, 1964, pp. 238-246, 2006.

[24] Kwon E. and Pitt S., Evaluation of emergency evacuation strategies for downtown event traffic using a dynamic network model. Transportation Research Record, 1964, pp. 238-246, 2006.

[25] United States Department of Transportation, Catastrophic Hurricane Evacuation Plan Evaluation, 2006. Source:http:// www.fhwa.dot.gov/ reports/hurricanevacuation/rtc chep eval.pdf (last access, 10-07-2011).

[26] Xie, C. and Turnquist, M.A. Integrated evacuation network optimization and emergency vehicle assignment. Transportation Research Board $88^{\text {th }}$, 2009.

[27] Shiomi, Y., Seto, Y. and Uno, N., A medical facilities location model considering road network vulnerability and accessibility. Transportation Research Board 90 $0^{\text {th }}, 2011$. 
[28] Ben Akiva M. and Lerman S. R., Discrete choice analysis: theory and application to travel demand, MIT Press, Cambridge, Mass, 1985.

[29] Sheffy Y., Urban transportation networks, Prentice Hall, Englewood Cliff, NJ, 1985.

[30] Ben Akiva M., Bergman M. J., Daly A.J. and Ramaswamy R., Modelling interurban route choice behaviour. In Proceedings of the $9^{\text {th }}$ International Symposium on Transportation and Traffic Theory, VNU Science Press, pp. 299-330, 1984.

[31] Antonisse R. W., Daly A.J. and Ben Akiva M., Highway assignment method based on behavioural models of car driver's route choice. Transportation Research Record, 1220, pp. 1-11, 1985.

[32] Russo, F. and Vitetta A., An assignment model with modified Logit, which obviates enumeration and overlapping problems. Transportation , 30, pp. 117-201, 2003.

[33] Cova, J. T., and J.P. Johnson. A network flow model for lane-based evacuation routing. Transportation Research Part A, 37, pp. 579-604, 2003.

[34] Takahashi N., K. Uchida, S. Kagaya and Asano M., Disaster impact analysis of limited access through traffic network model: the case of mt. Usu eruption. In Proceedings of the Eastern Asia Society for Transportation Studies, 5 , pp. 2441 - 2453, 2005.

[35] Sumalee A. and Kurauchi F., Network Capacity Reliability Analysis Considering Traffic Regulation after a Major Disaster. Networks and Spatial Economics, 6 , pp. 205-219, 2006.

[36] Mahamassani H, Dynamic network traffic assignment and simulation methodology for advanced system management applications. Networks and Spatial Economics, 1, pp. 267-297, 2001.

[37] Magnanti, T. L. and Wong R.T. Network Design and Transportation Planning: Models and Algorithms. Transportation Science, 18, pp. 1-55, 1984.

[38] Quattrone A. and Vitetta A., Random and fuzzy utility models for road route choice. Transportation Research Part E: Logistics and Transportation Review, 47(6), pp. 1126-1139, 2011.

[39] Prato C. G. and Bekhor S., Applying Branch-and-Bound technique to route choice set generation. Transportation Research Record, 1985, pp. 19-28, 2006.

[40] Hoogendoorn-Lanser S., Bovy P. and van Nes R., Application of constrained enumeration approach to multimodal choice set generation. Transportation Research Record, 1981, pp. 50-57, 2007.

[41] Miller-Hooks, E.D. and Mahmassani H.S., Least possible time paths in stochastic, time-varying networks. Computers Operations Research, 25 (12), pp. 1107-1125, 1998.

[42] Miller-Hooks E.D. and Mahmassani H.S.: Least expected time paths in stochastic, time-varying transportation networks. Transportation Science, 34 (2), pp. 198-215, 2000. 
[43] Teng H., Kaseko M., Xie G. and Kwigizile V., Evaluation of the impacts of emergency vehicle signal pre-emption. Transportation Research Board 87, 2008.

[44] Yang S., Hamedi M. and Hagani A., Online dispatching and routing model for emergency vehicles with area coverage constraints. Transportation Research Record, 1923, pp. 1-8, 2005.

[45] Mauga T. and M. Kaseko. Modeling of urban interaction between emergency vehicles and other vehicles. Transportation Research Board 86, 2007.

[46] Yuan F., Han L.D., Chin S.-M. and Hwang H., Proposed framework for simultaneous optimization of evacuation traffic destination and route assignment. Transportation Research Record, 1964, pp. 50-58, 2006.

[47] Robinson M.R. and Khattak A., Traffic information source selection and use in emergency situations. Transportation Research Board 90, 2011.

[48] Wang T. and Li Y., Research on the method of dynamic emergency rescue vehicle routing based on real-time information. Advances in Intelligent Systems Research, Atlantis Press, pp. 105-112, 2010.

[49] Shen Z. J. M., Pannala J., Rai R. and Tsoi T. S., Modeling transportation networks during disruptions and emergency evacuations. Transportation Research Board $88^{\text {th }}$ Annual Meeting, 2009, CD-ROM.

[50] Miller-Hooks E.D. and Mahmassani H.S., Path comparisons for a priori and time adaptive decisions in stochastic, time-varying networks. Computers Operations Research, 146, 67-82, 2003.

[51] Musolino G. and Vitetta A., Short-term forecasting in road evacuation: calibration of a travel time function. WIT Transactions on the Built Environment, Volume 116, Urban Transport XVII, Urban Transport and the Environment in $21^{\text {st }}$ Century, Pratelli \& Brebbia C. A. (ed.), WIT Press, Southampton, pp. 615-626, 2011.

[52] Polimeni A. and Vitetta A., Dynamic vehicle routing in road evacuation: a model for route design. WIT Transactions on the Built Environment, Volume 116, Urban Transport XVII, Urban Transport and the Environment in $21^{\text {st }}$ Century, Pratelli \& Brebbia C. A. (ed.), WIT Press, Southampton, pp. 627-638, 2011.

[53] Polimeni A. and Vitetta A., Dynamic vehicle routing in road evacuation: route design experimentation. WIT Transactions on the Built Environment, Volume 117, Safety and Security engineering IV, Guarascio M., Reiners G. Brebbia C. A. \& Garzia F. (ed.), WIT Press, Southampton, pp. 391-402, 2011.

[54] Laporte G., What You Should Know about the Vehicle Routing Problem, 2007 [on line]. Source: www.gerad.ca/en/publications (last access 8/07/11).

[55] Russo F., Polimeni A. and Vitetta A., Goods movement simulation in urban areas: a proposed approach. Trasporti Europei, 46(3), pp. 3-23. ISSN 1825 3997, 2010.

[56] Russo F., Polimeni A. and Vitetta A., From single path to Vehicle Routing: The retailer delivery approach. Procedia - Social and Behavioral Sciences, Volume 2, Issue 3, pp. 6378-6386, 2010. 
[57] Liao T.Y., Hu T.Y. and Chen D.J., Object-oriented evaluation framework for dynamic vehicle routing problems under real-time information. Transportation Research Board 87, 2008.

[58] Ting C.J. and Chen C.H., A combination of multiple ant colony system and simulated annealing for the multi-depot vehicle routing problem with time windows. Transportation Research Board 87.

[59] Giesen R., Mahmassani H.S. and Jaillet P., Strategies for online inventory routing problem under real-time information. Transportation Research Record, 1223, pp. 164-179, 2005.

[60] Gao S., Frejinger E. and Ben-Akiva M.E., Adaptive route choice models in stochastic time-dependent networks. Transportation Research Board 87, 2008.

[61] Liu D., Han J. and Zhu J., Vehicle routing for medical supplies in largescale emergencies. In The First International Symposium on Optimization and Systems Biology (OSB'07) Beijing, China, August 8-10, 2007.

[62] Gendreau M., Laporte G. and Semet F., A dynamic model and parallel tabu search heuristic for real-time ambulance relocation. Parallel Computing, 27, pp. 1641-1653, 2001.

[63] Gendreau M., Laporte G. and Semet F., The maximal expected coverage relocation problem for emergency vehicles. Journal of the Operational Research Society, 57, pp. 22-28, 2006.

[64] Rajagopalan H. K., Saydam C., Xiao J., A multiperiod expected covering location model for dynamic redeployment of ambulances. Computer and Operation Research, 35, pp. 814-826, 2008.

[65] Brotcorne L., Laporte G. and Semet F., Ambulance location and relocation models. European Journal of Operational Research, 147, pp. 451-463, 2003.

[66] Nair R. and Miller-Hooks E., Evaluation of relocation strategies for emergency medical service vehicles. In Transportation Research Board 88, 2009.

[67] Crèput J.C., Hajjam A., Koukam A. and Kuhn O., Dynamic vehicle routing problem for medical emergency management. In Self Organizing Maps Applications and Novel Algorithm Design, 2011.

[68] Zhu J., Gao M. and Huang J., A robust approach to vehicle routing for medical supplies in large scale emergencies. International symposium on emergency management, pp. 535-538, 2009.

[69] Araz C., Selim S. and Ozkarahan I., A fuzzy multi-objective coveringbased vehicle location model for emergency services. Computers \& Operations Research, 34, pp. 705-726, 2007.

[70] Shen Z., Dessouky M. and Ordóñez F., The stochastic vehicle routing problem for large scale emergencies. Source: http:// citeseerx.ist.psu.edu (last access, 07-11-2011).

[71] Jotshi A., Gong Q. and Batta R., Dispatching and routing of emergency vehicles in a disaster environment using data fusion. Socio-Economics Planning Sciences, 43, pp. 1-24, 2008. 
[72] Shiwei H., Zhang L., Song R., Wen Y. and Wu Y. Optimal transit routing problem for emergency evacuations. Transportation Research Board 88, 2009.

[73] Song R., Shiwei H. and Zhang L. Optimum transit operations during emergency evacuations. Transportation Research Board 88, 2009.

[74] Xie C. and Turnquist M.A., Integrated evacuation network optimization and emergency vehicle assignment. TRB 2009 Annual Meeting, 2009.

[75] Kappner A.S. and Bookhuis K.A., Field research concerning contraflow as a measure for massive evacuation. Procedia engineering, 3, pp. 77-86, 2010. 